AperTO - Archivio Istituzionale Open Access dell'Università di Torino

\title{
Wood dust and urinary 15-F2t isoprostane in Italian industry workers
}

\section{This is the author's manuscript}

Original Citation:

Availability:

This version is available http://hdl.handle.net/2318/1695536

since 2019-04-03T16:00:20Z

Published version:

DOI:10.1016/j.envres.2019.03.058

Terms of use:

Open Access

Anyone can freely access the full text of works made available as "Open Access". Works made available under a Creative Commons license can be used according to the terms and conditions of said license. Use of all other works requires consent of the right holder (author or publisher) if not exempted from copyright protection by the applicable law. 


\section{Wood dust and urinary $15-F_{2 t}$ isoprostane in Italian industry workers}

2 Roberto Bono $^{\mathrm{a}}$, Fabio Capacci ${ }^{\mathrm{b}}$, Filippo Cellai ${ }^{\mathrm{c}}$, Carla Sgarrella $^{\mathrm{b}}$, Valeria Bellisario ${ }^{\mathrm{a}}$, Giulia Trucco $^{\mathrm{a}}$, 3 Lorenzo Tofani ${ }^{d}$, Alessio Peluso ${ }^{e}$, Carla Poli ${ }^{f}$, Luciano Arena ${ }^{f}$, Sara Piro ${ }^{g}$, Lucia Miligi ${ }^{g}$, Armelle 4 Munnia $^{\mathrm{c},}$ and Marco Peluso ${ }^{\mathrm{c}, *}$

$5 \quad{ }^{a}$ Department of Public Health and Pediatrics, University of Turin, Italy

$6 \quad{ }^{b}$ Functional Unit for Prevention, Health and Safety in the Workplace, ASL10, Florence, Italy

$7{ }^{c}$ Cancer Factor Risk Branch, Regional Cancer Prevention Laboratory, ISPRO-Study, Prevention 8 and Oncology Network Institute, 50139 - Florence, Italy

$9{ }^{d}$ Department of Neurosciences, Psychology, Drug Research and Child Health, University of 10 Florence, Florence, Italy

11 e Statistician, Florence, Italy

$12{ }^{f}$ Department of Prevention, ASL11, Empoli, Florence, Italy

$13{ }^{g}$ Unit of Environmental and Occupational Epidemiology, ISPRO-Study, Prevention and Oncology 14 Network Institute, 50139 - Florence, Italy

15 "Correspondence to: Cancer Factor Risk Branch, Regional Cancer Prevention Laboratory, ISPRO16 Study, Prevention and Oncology Network Institute, 50139 - Florence, Italy. E-mail address: 17 m.peluso@ispro.toscana.it 
Wood dust is one of the most common occupational exposures, with about 3.6 million of workers in the wood industry in Europe. Wood particles can deposit in the nose and the respiratory tract and cause adverse health effects. Occupational exposure to wood dust has been associated with malignant tumors of the nasal cavity and paranasal sinuses. The induction of oxidative stress and the generation of reactive oxygen species through activation of inflammatory cells could have a role in the carcinogenicity of respirable wood dust. Therefore, we conducted a cross-sectional study to evaluate the prevalence of urinary $15-\mathrm{F}_{2 t}$ isoprostane $\left(15-\mathrm{F}_{2 \mathrm{t}}-\mathrm{IsoP}\right)$, a biomarker of oxidative stress and peroxidation of lipids, in 123 wood workers compared to 57 unexposed controls living in Tuscany region, Italy. $15-F_{2 t}-$ IsoP generation was measured by ELISA. The main result of the present study showed that a statistically significant excess of this biomarker occurred in the workers exposed to $1.48 \mathrm{mg} / \mathrm{m}^{3}$ of airborne wood dust with respect to the unexposed controls $\left(0.05 \mathrm{mg} / \mathrm{m}^{3}\right)$. The overall mean ratio (MR) between the workers exposed to wood dust and the controls was 1.36, 95\% Confidence Interval (C.I.) 1.18-1.57, after correction for age and smoking habits. A significant increment of $15-\mathrm{F}_{2 \mathrm{t}}-\mathrm{IsoP}(43 \%)$ was observed in the smokers as compared to the non-smokers. The urinary excretion of $15-\mathrm{F}_{2 t}-\mathrm{IsoP}$ was significantly associated with co-exposure to organic solvents and formaldehyde, i.e., MR of 1.41, 95\% C.I. 1.17-1.70, after adjustment for age and smoking habits. A $41 \%$ excess was observed in long-term wood workers, $95 \%$ C.I. 1.14-1.75. Multivariate regression analysis showed that the level of $15-\mathrm{F}_{2 \mathrm{t}}$-IsoP was linearly correlated to the length of exposure, regression coefficient $(\beta)=0.244 \pm 0.002$ (SE). The overall increment by exposure group persisted after stratification for smoking habits. For instance, in smokers, a $53 \%$ excess was detected in the wood workers as compared to the controls, $95 \%$ C.I. 1.23-1.91. Our data support the hypothesis that oxidative stress and lipid peroxidation can have a role in the toxicity of wood dust $\mathrm{F}_{2}$-IsoP measure can be a tool for the evaluation of the effectiveness of targeted interventions aimed to reduce exposures to environmental carcinogens.

Key words: wood dust, organic solvents, formaldehyde, 15- $\mathrm{F}_{2 \mathrm{t}}$ isoprostane, primary prevention, occupational health. 


\section{Introduction}

Wood dust is one of the most common occupational exposures, with about 3.6 million of workers in the wood industry in Europe (Kauppinen et al., 2006). Wood particles can deposit in the nose and the respiratory tract and cause adverse health effects (Çelik and Kanık, 2006). Epidemiological studies have indeed associated the exposure to wood dust to sinonasal cancers (SNC) (Acheson et al., 1968; Ball, 1968). In 1960, the first association with SNC was shown in the wood industry (Acheson et al., 1968). In 1995, this agent was classified as carcinogenic to humans (Group 1) by the International Agency for Research on Cancer (IARC) based mostly on a SNC excess (IARC, 1995). In 2012, the IARC confirmed the human carcinogenicity of wood dust and reported the first link with nasopharynx cancer (IARC, 2012). Considering other types of cancer, a meta-analysis has suggested a relationship with lung cancer (Hancock et al., 2015), but a significant influence of the geographic region was apparent.

SNC has been under compulsory surveillance since 2008 in Italy, through the "Sinonasal Cancer National Registry" (Registro Nazionale Tumori Naso-Sinusali: ReNaTuNS), a nationwide cancer registry coordinated by the National Institute for Insurance Against Accidents at Work (Istituto Nazionale per l'Assicurazione contro gli Infortuni sul Lavoro: INAIL) (Binazzi et al., 2017). Currently, the registry covers a proportion of Italy through regional structures devoted to the active search for cases from hospitals, to the definition of the modalities of exposure and has recorded 1,529 cases between 2000-2016. A study conducted by Demers et al. (Demers et al., 1995) found a doubled risk statistically significant for sinonasal cancer in men employed in any wood-related job $(\mathrm{OR}=2.0,95 \% \mathrm{Cl}: 1.6$ to 2.5$)$ in comparison to men who had never worked in a wood-related job. The increased risk was found among sawmill workers (OR $=2.5,95 \% \mathrm{Cl}: 1.8$ to 3.4 ), furniture workers (OR $=4.5,95 \% \mathrm{Cl}: 3.2$ to 6.5 ) and carpenters (OR $=2.9,95 \% \mathrm{Cl}: 2.1$ to 3.9 ), while no excess risk was observed among forestry, logging, pulp and paper workers. An increasing risk was detected in relation to the duration of exposure, and lagging exposure by 5, 10 or 20 years increased the strength of the association between duration of employment and sinonasal adenocarcinoma. Elevated risk for adenocarcinoma of the nasal cavity and paranasal sinuses (ADCN), a SNC subtype frequently associated with wood dust exposure (IARC, 2012), OR 58.6, $95 \%$ C.I. 23.74-144.8, was even reported among wood workers of the Piedmont region, Italy (d'Errico et al., 2009). Stronger ADCN risk, OR 179.9, 95\% C.I. 55.37-584.4, was found among those workers exposed to high level of wood dust (d'Errico et al., 2009).

Higher levels of oxidative damage, measured by the micronucleus and the comet assays in blood, buccal and nasal cells, have been detected in wood workers compared to unexposed controls (Bruschweiler et al., 2016; Palus et al., 1999; Rekhadevi et al., 2009). An enhanced risk for chromosomal instability was found in wood workers (Bruschweiler et al., 2014; Çelik and Kanık, 2006; Rekhadevi et al., 2009). Discrepant results have been reported (Wultsch et al., 2015). In that study, no induction of micronuclei was observed in wood workers exposed to $0.39-0.66 \mathrm{mg} / \mathrm{m}^{3}$ wood dust levels. Thus, further investigation into wood workers' occupational exposures are warranted. Furthermore, co-exposures to chrome, organic solvents, tannins, formaldehyde, textile dust and pesticides have been reported in the wood industry (Binazzi et al., 2017).In 2012, IARC suggested that the cancer risk of wood workers could be associated with the inflammatory reactions following wood dust exposure rather than to the direct action of this carcinogen (IARC, 2012). Inflammatory cells can generate a large spectrum of proinflammatory mediators and free radicals (Pylkkänen et al., 2009). Excessive production of reactive oxygen species (ROS) can cause damage to lipids, proteins and DNA (Marnett, 2000). Peroxidation of lipids (LPO) can lead to the production of aldehydes, such as malondialdehyde and 4-hydroxynonenal (Marnett, 2000), as well as to secondary oxidation products such as a series of prostaglandin-like products termed isoprostanes (IsoPs) (Roberts and Morrow, 2000).

IsoPs are compounds generated from the non-enzymatic free radical-catalyzed peroxidation of arachidonic acid and other highly unsaturated polyunsaturated fatty acids (Janicka et al., 2010). IsoPs can be grouped into 4 subfamilies, denoted as 5-, 12-, 8-, or 15-series regioisomers, depending on the carbon atom to which the side chain hydroxyl is attached. Among the three major classes of IsoPs $\left(F_{2^{-}}, D_{2^{-}}\right.$and $\left.E_{2^{-}}\right), F_{2^{-}}$IsoPs are recognized as the most suitable biomarker for 
their chemical stability (Roberts and Morrow, 2000). The measurement of this biomarker is widely used for the analysis of endogenous oxidative stress following ROS production and peroxidation of lipids (Basu, 2008). $\mathrm{F}_{2}$-IsoPs are more advantageous over other LPO biomarkers because they can be detected in a variety of biological samples including plasma, urine, lavage fluid and red blood cells (Milne et al., 2015). As IsoPs generate from LPO, their amounts provide an integrated measurement of unbalanced oxidant-antioxidant status (Lowe et al., 2013; Montuschi et al., 2004).

In the current study, we have investigated the potential effects of occupational exposure to wood dust in the wood product manufacturing sector in the Tuscany Region of Italy. A cross-sectional study was conducted to analyze the concentration of a biomarker of oxidative stress and LPO (15$\mathrm{F}_{2 t}-\mathrm{IsoP}$ ) in the workers exposed to wood dust. One of the main advantages of using biomarkers is that one can study signals of carcinogen exposure without having to wait for health effects as in classical epidemiological studies (Merlo et al., 1997; Munnia et al., 2017; Munnia et al., 2007; Peluso et al., 1997; Peluso et al., 2012). Although $F_{2}$-IsoP can be evaluated in different biological fluids, we employed urine due to its ready availability and the high stability of $\mathrm{F}_{2}$-IsoP in this medium (Morrow et al., 1999). Since obesity has been associated with increased F2-IsoP concentrations (Annor et al., 2017; Il'yasova et al., 2015), we have examined the relationships between urinary $\mathrm{F}_{2}$-IsoPs and weight gain. Further understanding of the link between wood dust and oxidative stress will improve knowledge of the mechanisms of carcinogenicity of this occupational agent. Novelty of the current study is based on various items, including larger sample size, a different geographical area, and a different type of data, i.e., the measurement of $\mathrm{F}_{2}$-IsoPs in urine rather that of micronucleus and DNA strand-breaks in blood, buccal and nasal cells.

\section{Material and methods}

\subsection{Subjects and sampling}

A sample of 44 wood companies of the province of Florence, Tuscany, Italy was randomly selected among those which are under compulsory health surveillance. Wood companies were contacted in person by medical doctors with qualifications in occupational medicine. The inclusion criteria were as follows: (a) only workers exposed to wood dust from wood industry; (b) only workers with a minimal exposure time of 1 year; (c) only controls without occupational history in industries entailing exposure to known or suspected carcinogens; and (d) only controls resident in areas with no proximity to major air pollution sources. All the volunteers involved in the study live and work in the province of Florence, Tuscany, Italy. A 15- $\mathrm{F}_{2} \mathrm{t}-\mathrm{IsoP}$ was determined using spot urine samples collected in the morning at each workplace. Wood workers and the other subjects were contacted by the local occupational health services. All the volunteers were informed about the study aim and gave a written informed consent. A life-style questionnaire was filled by each participant (Peluso et al., 2015). Detailed information on socio-demographic and anthropometric characteristics, education level, exposure to active and passive tobacco smoke, occupational exposure to wood dust, protective gear use, co-exposures to organic solvents, welding and motor exhaust fumes and occupational history were obtained. Subjects who had never smoked were classified as nonsmokers, smokers who had quitted smoking from at least one month prior were classified as exsmokers, while individuals who smoked at least one cigarette per day were classified as smokers. The Body Mass Index (BMI) categories reported from the National Heart National Heart, Lung, and Blood Institute (https://www.nhlbi.nih.gov/) were used for grouping the study participants in normal weight persons $\left(18.5-24.9 \mathrm{~kg} / \mathrm{m}^{2}\right)$, overweight persons $\left(25-25.99 \mathrm{~kg} / \mathrm{m}^{2}\right)$ and obese persons $(\geq 30$ $\mathrm{kg} / \mathrm{m}^{2}$ ). BMI was determined using self-reported weight and height. Study procedures were performed in accordance with the Declaration of Helsinki for human studies and the guidelines of the General Hospital Institutional Committee that reviewed and approved the present protocol.

\subsection{Exposure data}

Data on carcinogen exposure are collected by employers and regularly sent to the Italian Institute for Occupational Safety and Prevention (ISPESL) (Italian legislative decree no. 626 of 19 September 1994). Such information is named exposure registries and includes quantitative measurements of wood dust exposure. Companies are responsible for collecting the exposure 
measurements in accordance with the EN 689:1995 regulation by the European Committee on Standardization (Scarselli et al., 2008). For the purpose of this research, data on occupational exposure measurements of wood dust recorded in the Information System for Recording Occupational Exposures to Carcinogens (SIREP) were used to estimate environmental air concentrations.

\subsection{Urinary $15-F_{2 t}$ isoprostane and creatinine measurement}

The IsoP under investigation consists of one of the most abundant endogenous $F_{2}$-IsoPs, i.e., the $15-\mathrm{F}_{2 \mathrm{t}}$-IsoP, a biomarker considered to be representative for human oxidant status (Milne et al., 2015), also referred to as 8-iso-prostaglandin $F_{2 a}$ (Roberts and Morrow, 2000). In the current study, the concentrations of $15-\mathrm{F}_{2 t}-$ IsoP were analyzed using the competitive enzyme-linked immunoassay (ELISA) with a specific microplate kit (Oxford, MI, USA), according to the manufacturer's instructions, as previously reported (Bono et al., 2015; Romanazzi et al., 2013). In order to normalize urinary dilution rate of $15-\mathrm{F}_{2 t}$-IsoP an aliquot of urine was used to quantify the concentration of creatinine by the kinetic Jaffé procedure (Bartels and Cikes, 1969).

\subsection{Statistical analysis}

The level of $15-\mathrm{F}_{2 \mathrm{t}}$-IsoP was expressed as $\mathrm{ng} / \mathrm{mg}$ creatinine. Given the right-skewed distribution of this biomarker, the data were log transformed to stabilize the variance and normalize the distribution. Multivariate statistical analyses were applied using log-normal regression models including age (continuous), tobacco smoking, i.e., non-smokers, ex-smokers, smokers, occupational history (years), and BMI, as predictive variables to evaluate the association between exposure to wood dust and the urinary excretion of $15-F_{2 t}-I$ soP in the study participants. Results were adjusted for age and smoking. This was based on a previous study showing potential associations between these variables and biomarker levels (Ceppi et al., 2011). Wood workers were classified according to occupational exposures in two additional sub-groups: a) wood workers exposed to wood dust alone and b) wood workers with co-exposures to organic solvents. The regression parameters estimated from the models were interpreted as ratios [Means Ratio (MR)] between the means of $15-\mathrm{F}_{2 \mathrm{t}}$-IsoPs of each level of the categorical variables with respect to the reference level, as appropriate. The MR was used as a measure of effect (van Houwelingen et al., 2002). A p-value of $<0.05$ (two-tailed) was considered significant. Data were analyzed using SAS9.3 and SPSS 20.0 (IBM SPSS Statistics, New York, NY).

\section{Results}

\subsection{Study population}

The underlying basic population consisted of workers employed in the wood product manufacturing sector of the province of Florence, Tuscany Region, Italy. 32 out of 44 consented to participate to the study. Participation rates were $\sim 95 \%$. The concentration of $15-\mathrm{F}_{2 \mathrm{t}}$-IsoPs in the wood workers was evaluated along with control subjects, i.e., 123 wood workers and 57 controls. All participants were males with a mean age of $45.3 \pm 0.85$ years and $35 \%$ of which were smokers. In the current study, the wood workers consisted of carpenters and joiners, wood processing-plant operators, woodworking machine operators, wood products assemblers, manufacturing labourers, industrial robot operators and other wood related workers. The use of the most common Personal Protective Equipment (PPE) in woodworking, i.e., disposable respirators, was generally reported from majority of the wood workers. Controls were living in residential areas with no proximity to major air pollution sources. The two groups had similar demographic, anthropometric and life-style characteristics. The mean age of the wood workers and the controls was not statistically different (Table 1). The average values of BMI were similar among the two groups (Table 1). The frequency of smokers was similar between the groups, i.e., $36 \%$ of the wood workers and $37 \%$ of the controls, respectively. The distribution of subjects with respect to wood dust exposure with - out co-exposures to other airborne carcinogens and smoking habits was reported in Table 2. Other variables included length of employment and BMI groups (Tables 1-2). 


\subsection{Exposure data}

The exposure measurement of wood dust air concentrations corresponds to a single value assessed from several consecutive samples by fixed positions (Scarselli et al., 2008). Airborne levels of industrial contaminants were quantified by daily mean concentration, i.e., 8-h timeweighted average (TWA-8), of respirable wood dust among exposed workers. The mean level of TWA-8 concentration of wood dust was $1.48 \mathrm{mg} / \mathrm{m}^{3}$ in wood workers.

\subsection{Urinary $15-F_{2 t}$ isoprostane level, smoking habits and occupational exposure}

An increased amount of $15-\mathrm{F}_{2 t}-\mathrm{IsoP}$ was found in the urine of wood workers as compared to the controls (4.2 vs $2.9 \mathrm{ng} / \mathrm{mg}$ creatinine, Table 2). The multivariate analysis shows that the $36 \%$ excess of $15-\mathrm{F}_{2 \mathrm{t}}$-IsoP of the wood workers was significantly higher as compared to the controls, $95 \%$ C.I. 1.18-1.57. Smokers had an average concentration of $15-\mathrm{F}_{2 \mathrm{t}}$-IsoP higher than ex-smokers and non-smokers. A significant excess was found in the smokers in respect to the non-smokers, 95\% Confidence Interval (C.I.) 1.23-1.66, after adjusting for age by statistical analysis. Subsequently, the effect of co-exposures to other potential occupational carcinogens in the wood industry on the level of $15-\mathrm{F}_{2 \mathrm{t}}-\mathrm{IsoP}$ was investigated. Therefore, workers were stratified into two additional sub-groups: a) only wood dust exposed workers and b) mixed exposed workers. Table 2 indicates that the highest level of $15-\mathrm{F}_{2 \mathrm{t}}$-IsoP occurred in the wood workers who were co-exposed to respirable organic solvents in respect to those who were only exposed to wood dust (4.5 and 4.0 $\mathrm{ng} / \mathrm{mg}$ creatinine, respectively). After adjusting for age and smoking, the multivariate analysis shows a $41 \%$ increment of $15-\mathrm{F}_{2 t}$-IsoP, $95 \%$ C.I. 1.17-1.70, in the mixed exposed workers, whereas a lower increment was observed in the only wood dust exposed workers, 95\% C.I. 1.151.56. When we considered occupational history, there was a greater production of $15-\mathrm{F}_{2 \mathrm{t}}-\mathrm{IsoP}$ in the long-term wood workers $\left(4.8 \mathrm{ng} / \mathrm{mg}\right.$ creatinine of $\left.15-\mathrm{F}_{2 \mathrm{t}}-\mathrm{IsoP}\right)$ compared to those with shorter occupational history $\left(3.2 \mathrm{ng} / \mathrm{mg}\right.$ creatinine). A $41 \%$ excess of $15-\mathrm{F}_{2 \mathrm{t}}$-lsoP was observed in the wood workers with longer occupational exposure times, 95\% C.I. 1.14-1.75. Then, the excretion of $15-\mathrm{F}_{2 t}$-IsoPs was found to be significantly correlated with the length of dust exposure $(\mathrm{p}$-value $=$ 0.007). Table 3 reports the mean concentrations of $15-\mathrm{F}_{2 t}-\mathrm{IsoP}$ and $\mathrm{MR}$ and $95 \%$ C.I. by exposure group and smoking stratification. The highest amount of $15-\mathrm{F}_{2 t}-\mathrm{IsoP}$ was found in the wood workers who were smokers, i.e., $5.0 \mathrm{ng} / \mathrm{mg}$.

\subsection{Urinary $15-F_{2 t}$ isoprostane level and BMI groups}

Since early studies have supported the hypothesis of a relationship between $\mathrm{F}_{2}$-IsoP and weight gain (Annor et al., 2017; Il'yasova et al., 2015), the association of this biomarker of oxidant status with BMI was investigated. Study participants were divided by three BMI categories: a) normal weight persons $\left(18.5-24.9 \mathrm{~kg} / \mathrm{m}^{2}\right)$, b) overweight persons $\left(25-25.99 \mathrm{~kg} / \mathrm{m}^{2}\right)$ and c) obese persons $\left(\geq 30 \mathrm{~kg} / \mathrm{m}^{2}\right)$ to evaluate the relationship of $F_{2}$-IsoP with increase in body weight that could result in excessive fat accumulation. Table 2 shows that the mean concentrations of $15-\mathrm{F}_{2 \mathrm{t}}-\mathrm{IsoP}$ of obese and overweight participants were higher than those with normal weight, but, no significant effect was found.

\section{Discussion}

Wood processing causes small particles of wood dust to become suspended in the air. Workers can inhale these particles, which can cause adverse health effects. The main result of this paper showed that significantly enhanced level of F2-IsoP occurred in the workers compared to the unexposed controls. A $36 \%$ excess of 15-F2t-IsoP levels was found in the wood workers as compared with the unexposed controls. Furthermore, the significant excess of 15-F2t-IsoP persisted after smoking habit stratification. Among the wood workers, a 53\% excess of $15-\mathrm{F} 2 \mathrm{t}$-IsoP was found in the smokers, a $48 \%$ excess was observed in the ex-smokers and a $27 \%$ in the nonsmokers as compared to the appropriate controls. The urinary excretion of this biomarker was significantly associated with other parameters, including smoking habits, co-exposure to other airborne carcinogens and length of employment. In particular, multivariate regression analysis showed that the level of 15-F2t-IsoP was linearly correlated to the length of exposure. In 
agreement with our findings, other studies have previously reported increased oxidative stress generation in relation to occupational exposure to wood dust (Bruschweiler et al., 2016; Palus et al., 1999; Rekhadevi et al., 2009). Our findings provide strengthening of the hypothesis that oxidative stress and LPO can have a main role in the toxicity of wood dust. The analysis of F2-IsoP in urine could offer a unique noninvasive analytic tool to study the role of ROS in chronic occupational exposures. In the current case, the linkage between urinary 15-F2t-IsoPs and wood dust can be due to an increased production of ROS caused by inflammation after exposure fine and abundant airborne dust created during wood manipulation, maintenance activities and cleaning equipment. Increased oxidative stress and LPO can be caused from the oxidative burst of activated macrophages and neutrophils, cells with a main role in phagocytosis and clearance of xenobiotic particles, and from increased inflammatory cytokines and activated leukocytes (Gungor et al., 2010; Vanhees et al., 2013). This is in keeping with the results of previous studies using a biomarker of oxidative DNA damage and LPO (Bonassi et al., 2017; Bono et al., 2016; Bono et al., 2010; Peluso et al., 2013; Peluso et al., 2010). In support of our hypothesis, free radicals produced through chronic inflammatory process and cancer disease have been implicated as the causal factor in the mutagenesis of the tumor suppressor gene TP53 (Brancato et al., 2016; PerezEscuredo et al., 2012).

Next, our study showed an empirical relationship between tobacco smoking and the urinary excretion of $15-\mathrm{F}_{2 \mathrm{t}}-\mathrm{IsoP}$, possibly related to the inhalation exposure to carcinogens contained in tobacco smoke. A $43 \%$ increment of the level of $15-\mathrm{F}_{2 \mathrm{t}}$-IsoP was present in overall the smokers as compared to the non-smokers. This excess is commonly interpreted as an harmful oxidative stress (Basu, 2008). These findings were somewhat expected as active smokers inhale a broad range of airborne carcinogens (IARC, 2004). The involvement of altered oxidative stress-related mechanisms in tobacco smoke carcinogenesis is in line with previous studies using various biomarkers of oxidative stress and LPO (Munnia et al., 2004; Peluso et al., 2014; Romanazzi et al., 2013). Various groups have measured the concentrations of $F_{2}$-IsoP in biological fluids of smokers. The mean level of free and esterified $F_{2}$-IsoP in the urine and plasma of smokers have been found to be significantly elevated as compared to non-smokers (Lowe et al., 2013). For instance, a previous cross-sectional study conducted on workers employed in an industry of plastic laminates in Piedmont, Italy, founds that smoking habits were significantly associated with the urinary excretion of $15-\mathrm{F}_{2 t}$-IsoP (Romanazzi et al., 2013). When the relationship of $15-\mathrm{F}_{2 t}$ - IsoP with BMI was investigated, we found that the levels of $15-\mathrm{F}_{2 \mathrm{t}}$-IsoP tended to increase with fat accumulations. The $42 \%$ of the obese subjects showed indeed higher excretion of $15-\mathrm{F}_{2 t}$-IsoP in respect to those with normal weight. This is partially in keeping with a previous work of Annor et al. (Annor et al., 2017 ) on the risk of diabetes and weight gain. In that study, the $35 \%$ of the obese individuals showed greater levels of $\mathrm{F}_{2}$-lsoPs as compared to the controls. Additional studies are necessary to understand if this biomarker can be used as measure of lifestyle habits and intervention targeted to obesity prevention.

The threshold exposure limit recommended by the Italian law is $5 \mathrm{mg} / \mathrm{m}^{3}$ (Legislative Decree No $66 / 2000$ ). This value will remain until the $2020^{\text {th }}$, after the entry into force of the new threshold exposure limit of $3 \mathrm{mg} / \mathrm{m}^{3}$ for five years and thereafter of $2 \mathrm{mg} / \mathrm{m}^{3}$ (European Directive Decree No 2017/2398). In this context, the SIREP database aims to facilitate analysis of occupational exposure figures for carcinogenic agents. In or study, the average amount of wood dust concentrations experienced from the wood workers was lower than threshold exposure limit of 3 $\mathrm{mg} / \mathrm{m}^{3}$ (i.e., $1.48 \mathrm{mg} / \mathrm{m}^{3}$ ). This result is consistent with that reported from a previous study of Scarselli et al. (Scarselli et al., 2008), where the mean concentrations of wood dust was of 1.44 $\mathrm{mg} / \mathrm{m}^{3}$ for 1.181 companies in Italy. Although our static measurements of the concentrations of industrial contaminants by fixed positions provide evidence of wood workers' exposure via air, they are not well representative of individual exposures to wood dust due to spatial and temporal variations. Therefore, we could not assess the potential relationships of airborne measurements with biomarker urinary excretion in exposed workers.

302 The airborne wood-dust concentrations from exposure registries are commonly used for the 303 purposes of hazard control, exposure surveillance and assessment of health risks (Kauppinen et 
al., 2006). Nevertheless, a limitation of our study is that no data on the variability of wood dust concentrations within a facility were available. The bias due to the variability of airborne carcinogen levels in occupational settings is difficult to predict, but a large variation can be present in one spot of a factory versus another. There could be an underestimation of the exposure to wood dust associated to some woodworking operations. For instance, local exhaust ventilation is used widely with fixed woodworking machinery, but it is generally lacking for hand tools (Pisaniello et al., 1991). The effects of poor work practices, such as the use of compressed air for cleaning, the lack of local exhaust ventilation for hand tools, that are commonly associated to high exposure levels to wood dust (Alwis et al., 1999), could be missed. Variations in the use of PPE (Alwis et al., 1999) and in the effective application of WorkSafe procedures at work places could have influenced the personal levels of exposure to wood dust of our workers.

Our subsequent finding shows that the urinary excretion of $15-\mathrm{F}_{2 \mathrm{t}}-\mathrm{Iso} \mathrm{P}$ in the workers exposed to wood dust can aggravate with co-exposure to other respiratory carcinogens. An excess of $41 \%$ was detected in the wood workers that were co-exposed to organic solvents compared to the controls. Conversely, a lower excess was determined in the only wood dust exposed workers. High biosynthesis of $\mathrm{F}_{2}$-IsoP can be due to frequent free radical-catalyzed reactions induced by alterations of oxidative stress, antioxidant defence and inflammation especially caused by occupational exposures to complex mixtures of airborne carcinogens. This is consistent with a cross-sectional study of workers exposed to dust containing silica (Peluso et al., 2015). In this study, the amount of oxidative stress and LPO biomarker of the workers exposed to airborne silica dust was greater in the case of occupational co-exposures to organic solvents, welding and motor exhaust fumes. Constituents of organic solvents, such as benzene and formaldehyde can be involved in the generation of oxidative stress and ROS (Bono et al., 2016; Bono et al., 2010; Sorensen et al., 2003) and cause the production of $15-\mathrm{F}_{2 \mathrm{t}}$-lsoP determined in the workers exposed to wood dust. Our results suggest that the urinary level of $\mathrm{F}_{2}$-IsoP resulting from exposures to airborne wood dust can be affected from concomitant carcinogen exposures. Levels of oxidative stress can increase with exposures to organic solvents (Salimi et al., 2017; Singh et al., 2010), leading to a greater imbalance between excessive ROS generation and their degradation by antioxidants. The induction of reactive species can increase damage to membrane lipids, cellular proteins and DNA.

334

335

336

337

338

339

340

341

342

343

344

345

346

347

348

349

350

351

352

353

354

355

A significant difference in the amount of $15-\mathrm{F}_{2 \mathrm{t}}$-IsoP was then observed among sub-groups of wood workers with different occupational history. The urinary excretion of this biomarker of oxidant status was significantly elevated in those subjects with longer exposure time. An $41 \%$ excess of $15-\mathrm{F}_{2 \mathrm{t}^{-}}$ IsoP was found in the long-term wood workers as compared to those with shorter exposures, used as the reference level. Multivariate regression analysis showed that the level of $15-F_{2 t}-$ IsoP was significantly linearly correlated to the length of employment, in agreement with a previous study on asbestos workers (Yoshida et al., 2001). In that study, the generation of an urinary biomarker of oxidative stress correlated positively with the length of exposure. Rekhadevi et al. (Rekhadevi et al., 2009) have similarly found an association between length of occupational exposure and increase frequency of micronuclei. Taken together, the occurrence of elevated oxidative stress in long-term wood workers can be possibly due to chronic inflammatory conditions. Our study suggests that the measure of urinary F2-IsoPs can serve as a biomarker for assessing occupational carcinogen exposure and improving workplace safety. Particular effort should bedevoted to studyinglong termhealth effects of exposure to wood dust,such as SNC.

Particular effort should be devoted to study delayed reactions such as diseases that take a long time to develop, like SNC, that can be caused by long-term exposure to this carcinogenic agent.

\section{Conclusions}

Our study provides a valuable contribution to the issue of oxidative stress in woodworking. An excessive ROS generation was demonstrated in exposed workers. Furthermore, we showed that exposure to organic solvents can increase the levels of urinary biomarkers of oxidative stress in wood workers. Results provide a basis for worker surveillance in occupational settings. $\mathrm{F}_{2}$-IsoP measure could be used for the evaluation of the effectiveness of targeted interventions aimed to 
356 reduce exposures to various environmental carcinogens. A more effective control of occupational health risks could decrease the incidence of illness at work and improve the health of the workforce. Acknowledgments

360 We are grateful to Dr. Dusca Bartoli, Dr. Giuseppe A. Farina, Dr. Tonina E. Iaia, Dr. Pierluigi Faina, 361 Dr. Luciano Monticelli for the assistances contacting with workers.

\section{Funding}

363 This work was supported by the Tuscany Region and the National Institute for Insurance Against 364 Accident at Work (INAIL).

\section{Declarations of interest}

366 None 


\section{References}

Acheson, E. D., et al., 1968. Nasal cancer in woodworkers in the furniture industry. Br Med J. 2, 587-596.

Alwis, U., et al., 1999. Dust Exposures in the Wood Processing Industry. Am Ind Hyg Ass J. 60, $641-646$.

Annor, F., et al., 2017. African Ancestry Gradient Is Associated with Lower Systemic F(2)-Isoprostane Levels. Oxid Med Cell Longev. 2017, 8319176-8319176.

Ball, M. J., 1968. Nasal cancer in woodworkers. Br Med J. 3, 253-253.

Bartels, H., Cikes, M., 1969. [Chromogens in the creatinine determination of Jaffe]. Clin Chim Acta. 26, 1-10.

Basu, S., 2008. F2-isoprostanes in human health and diseases: from molecular mechanisms to clinical implications. Antiox Redox Sign. 10, 1405-1434.

Binazzi, A., et al., 2017. Sinonasal cancer in the Italian national surveillance system: Epidemiology, occupation, and public health implications. Am J Ind Med. 1-12.

Bonassi, S., et al., 2017. 3-(2-deoxy- $\beta$-d-erythro-pentafuranosyl) pyrimido [1, 2- $\alpha$ ] purin-10 (3H)-one deoxyguanosine adducts of workers exposed to asbestos fibers. Toxic Lett. 270, 1-7.

Bono, R., et al., 2016. Formaldehyde-induced toxicity in the nasal epithelia of workers of a plastic laminate plant. Toxicol Res. 5, 752-760.

Bono, R., et al., 2010. Malondialdehyde-deoxyguanosine adduct formation in workers of pathology wards: the role of air formaldehyde exposure. Chem Res Toxicol. 23, 1342-8.

Bono, R., et al., 2015. Urban air and tobacco smoke as conditions that increase the risk of oxidative stress and respiratory response in youth. Environ Res. 137, 141-146.

Brancato, B., et al., 2016. 8-Oxo-7, 8-dihydro-2-deoxyguanosine and other lesions along the coding strand of the exon 5 of the tumour suppressor gene P53 in a breast cancer case-control study. DNA Res. 23, 395-402.

Bruschweiler, D. E., et al., 2016. DNA Damage among Wood Workers Assessed with the Comet Assay. Environ Health Insights. 10, 105-112.

Bruschweiler, E. D., et al., 2014. Workers exposed to wood dust have an increased micronucleus frequency in nasal and buccal cells: results from a pilot study. Mutagenesis. 29, 201-207.

Çelik, A., Kanık, A., 2006. Genotoxicity of occupational exposure to wood dust: Micronucleus frequency and nuclear changes in exfoliated buccal mucosa cells. Environ Mol Mutagen. 47, 693-698.

Ceppi, M., et al., 2011. Study design and statistical analysis of data in human population studies with the micronucleus assay. Mutagenesis. 26, 247-252.

d'Errico, A., et al., 2009. A case-control study on occupational risk factors for sino-nasal cancer. Occup Environ Med. 66, 448-455.

Demers, P. A., et al., 1995. Wood dust and sino-nasal cancer: pooled reanalysis of twelve case-control studies. Am J Ind Med. 28, 151-66.

Gungor, N., et al., 2010. Transcriptional profiling of the acute pulmonary inflammatory response induced by LPS: role of neutrophils. Respir Res. 11, 24.

Hancock, D. G., et al., 2015. Wood dust exposure and lung cancer risk: a meta-analysis. Occup Environ Med. 72, 889-898.

IARC, 1995. Wood Dust and Formaldehyde. IARC Monogr Eval Carcinog Risk Chem Hum. 62, 35-215.

IARC, 2004. Tobacco smoke and involuntary smoking. IARC Monogr Eval Carcinog Risks Hum. 83, 1-1438.

IARC, 2012. Wood Dust. A Review of Human Carcinogens: Arsenic, Metals, Fibres, and Dusts. IARC Monogr Eval Carcinog Risks Hum. 100 C, 1-469.

II'yasova, D., et al., 2015. Urinary F2-Isoprostanes and Metabolic Markers of Fat Oxidation. Oxid Medic Cell Long. 2015.

Janicka, M., et al., 2010. Isoprostanes-Biomarkers of Lipid Peroxidation: Their Utility in Evaluating Oxidative Stress and Analysis. IJMS. 11, 4631.

Kauppinen, T., et al., 2006. Occupational Exposure to Inhalable Wood Dust in the Member States of the European Union. Ann Occ Hyg. 50, 549-561.

Lowe, F. J., et al., 2013. Lung cancer biomarkers for the assessment of modified risk tobacco products: an oxidative stress perspective. Biomarkers. 18, 183-195.

Marnett, L. J., 2000. Oxyradicals and DNA damage. Carcinogenesis. 21, 361-70. 
Merlo, F., et al., 1997. Airborne levels of polycyclic aromatic hydrocarbons: 32P-postlabeling DNA adducts and micronuclei in white blood cells from traffic police workers and urban residents. J Environ Pathol Toxicol Oncol. 16, 157-62.

Milne, L. G., et al., 2015. The isoprostanes - 25 years later. BBA-Mol Cell Biol L. 1851, 433-445.

Montuschi, P., et al., 2004. Isoprostanes: markers and mediators of oxidative stress. FASEB. 18, $1791-1800$.

Morrow, J. D., et al., 1999. Quantification of the Major Urinary Metabolite of 15-F2t-Isoprostane (8-isoPGF2Î士) by a Stable Isotope Dilution Mass Spectrometric Assay. Anal Bioch. 269, 326-331.

Munnia, A., et al., 2004. Exocyclic malondialdehyde and aromatic DNA adducts in larynx tissues. Free Radic Biol Med. 37, 850-8.

Munnia, A., et al., 2017. Bulky DNA Adducts, Tobacco Smoking, Genetic Susceptibility, and Lung Cancer Risk. Adv Clin Chem. 81, 231-77.

Munnia, A., et al., 2007. 32P-Post-labelling method improvements for aromatic compound-related molecular epidemiology studies. Mutagenesis. 22, 381-5.

Palus, J., et al., 1999. DNA damage detected by the comet assay in the white blood cells of workers in a wooden furniture plant. Mutat Res. 444, 61-74.

Peluso, M., et al., 1997. Detection of DNA adducts in human nasal mucosa tissue by 32P-postlabeling analysis. Carcinogenesis. 18, 339-44.

Peluso, M., et al., 2012. DNA methylation differences in exposed workers and nearby residents of the Ma Ta Phut industrial estate, Rayong, Thailand. Int J Epidemiol. 41, 1753-60; author response 1761-3.

Peluso, M., et al., 2013. Malondialdehyde-deoxyguanosine and bulky DNA adducts in schoolchildren resident in the proximity of the Sarroch industrial estate on Sardinia Island, Italy. Mutagenesis. 28, 315-21.

Peluso, M., et al., 2010. Malondialdehyde-deoxyguanosine adducts among workers of a Thai industrial estate and nearby residents. Environ Health Perspect. 118, 55-9.

Peluso, M. E., et al., 2014. Aberrant methylation of hypermethylated-in-cancer-1 and exocyclic DNA adducts in tobacco smokers. Toxicol Sci. 137, 47-54.

Peluso, M. E., et al., 2015. Oxidatively damaged DNA in the nasal epithelium of workers occupationally exposed to silica dust in Tuscany region, Italy. Mutagenesis. 30, 519-25.

Perez-Escuredo, J., et al., 2012. Wood dust-related mutational profile of TP53 in intestinal-type sinonasal adenocarcinoma. Human Pathology. 43, 1894-1901.

Pisaniello, D. L., et al., 1991. Wood dust exposure during furniture manufacture -results from an Australian survey and consideration for threshold limit value development. Am Ind Hyg Ass J. 52, 485-492.

Pylkkänen, L., et al., 2009. Wood dusts induce the production of reactive oxygen species and caspase-3 activity in human bronchial epithelial cells. Toxic in Vitro. 262, 265-270.

Rekhadevi, P. V., et al., 2009. Genetic damage in wood dust-exposed workers. Mutagenesis. 24, 59-65.

Roberts, L. J., Morrow, J. D., 2000. Measurement of F2-isoprostanes as an index of oxidative stress in vivo. Free Radic Biol Med. 28, 505-513.

Romanazzi, V., et al., 2013. 15-F(2)t isoprostane as biomarker of oxidative stress induced by tobacco smoke and occupational exposure to formaldehyde in workers of plastic laminates. Sci Total Environ. 442, 20-5.

Salimi, A., et al., 2017. Xylene Induces Oxidative Stress and Mitochondria Damage in Isolated Human Lymphocytes. Toxic res. 33, 233-238.

Scarselli, A., et al., 2008. Occupational exposure levels to wood dust in Italy, 1996\&\#x2013;2006. Occup Environ Med. 65, 567-574.

Singh, M. P., et al., 2010. Effects of co-exposure of benzene, toluene and xylene to Drosophila melanogaster: Alteration in hsp70, hsp60, hsp83, hsp26, ROS generation and oxidative stress markers. Chemosphere. 79, 577-587.

Sorensen, M., et al., 2003. Linking exposure to environmental pollutants with biological effects. Mutat Res. 544, 255-71.

van Houwelingen, H. C., et al., 2002. Advanced methods in meta-analysis: multivariate approach and metaregression. Stat Med. 21, 589-624. 
Vanhees, K., et al., 2013. Intrauterine exposure to flavonoids modifies antioxidant status at adulthood and decreases oxidative stress-induced DNA damage. Free Radic Biol Med. 57, 154-61.

471 Wultsch, G., et al., 2015. Impact of exposure to wood dust on genotoxicity and cytotoxicity in exfoliated buccal and nasal cells. Mutagenesis. 30, 701-709.

474 Yoshida, R., et al., 2001. Urinary 8-oxo-7, 8-dihydro-2'-deoxyguanosine and biopyrrins levels among 475 construction workers with asbestos exposure history. Ind Health. 39, 186-8. 
1 Wood dust and urinary $15-\mathrm{F}_{2 \mathrm{t}}$ isoprostane in Italian industry workers

1

Roberto Bono ${ }^{a}$, Fabio Capacci $^{\mathrm{b}}$, Filippo Cellai ${ }^{\mathrm{c}}$, Carla Sgarrella ${ }^{\mathrm{b}}$, Valeria Bellisario ${ }^{a}$, Giulia Trucco $^{\mathrm{a}}$, Lorenzo Tofani ${ }^{d}$, Alessio Peluso ${ }^{e}$, Carla Poli ${ }^{f}$, Luciano Arena ${ }^{f}$, Sara Piro ${ }^{g}$, Lucia Miligi ${ }^{9}$, Armelle Munnia ${ }^{\mathrm{c},}$ and Marco Peluso ${ }^{\mathrm{c},}$

${ }^{a}$ Department of Public Health and Pediatrics, University of Turin, Italy

${ }^{b}$ Functional Unit for Prevention, Health and Safety in the Workplace, ASL10, Florence, Italy

${ }^{c}$ Cancer Factor Risk Branch, Regional Cancer Prevention Laboratory, ISPRO-Study, Prevention and Oncology Network Institute, 50139 - Florence, Italy

${ }^{d}$ Department of Neurosciences, Psychology, Drug Research and Child Health, University of Florence, Florence, Italy

e Statistician, Florence, Italy

${ }^{f}$ Department of Prevention, ASL11, Empoli, Florence, Italy

${ }^{g}$ Unit of Environmental and Occupational Epidemiology, ISPRO-Study, Prevention and Oncology Network Institute, 50139 - Florence, Italy

"Correspondence to: Cancer Factor Risk Branch, Regional Cancer Prevention Laboratory, ISPROStudy, Prevention and Oncology Network Institute, 50139 - Florence, Italy. E-mail address: m.peluso@ispro.toscana.it 


\section{Abstract}

Wood dust is one of the most common occupational exposures, with about 3.6 million of workers in the wood industry in Europe. Wood particles can deposit in the nose and the respiratory tract and cause adverse health effects. Occupational exposure to wood dust has been associated with malignant tumors of the nasal cavity and paranasal sinuses. The induction of oxidative stress and the generation of reactive oxygen species through activation of inflammatory cells could have a role in the carcinogenicity of respirable wood dust. Therefore, we conducted a cross-sectional study to evaluate the prevalence of urinary $15-\mathrm{F}_{2 t}$ isoprostane $\left(15-\mathrm{F}_{2 \mathrm{t}}-\mathrm{IsoP}\right)$, a biomarker of oxidative stress and peroxidation of lipids, in 123 wood workers compared to 57 unexposed controls living in Tuscany region, Italy. $15-\mathrm{F}_{2 \mathrm{t}}-\mathrm{Is} \mathrm{OP}$ generation was measured by ELISA. The main result of the present study showed that a statistically significant excess of this biomarker occurred in the workers exposed to $1.48 \mathrm{mg} / \mathrm{m}^{3}$ of airborne wood dust with respect to the unexposed controls $\left(0.05 \mathrm{mg} / \mathrm{m}^{3}\right)$. The overall mean ratio (MR) between the workers exposed to wood dust and the controls was 1.36, 95\% Confidence Interval (C.I.) 1.18-1.57, after correction for age and smoking habits. A significant increment of $15-\mathrm{F}_{2 \mathrm{t}}-\mathrm{IsoP}(43 \%)$ was observed in the smokers as compared to the non-smokers. The urinary excretion of $15-\mathrm{F}_{2 t}-\mathrm{IsoP}$ was significantly associated with co-exposure to organic solvents and formaldehyde, i.e., MR of 1.41, 95\% C.I. 1.17-1.70, after adjustment for age and smoking habits. A $41 \%$ excess was observed in long-term wood workers, $95 \%$ C.I. 1.14-1.75. Multivariate regression analysis showed that the level of $15-\mathrm{F}_{2 \mathrm{t}}$-IsoP was linearly correlated to the length of exposure, regression coefficient $(\beta)=0.244 \pm 0.002$ (SE). The overall increment by exposure group persisted after stratification for smoking habits. For instance, in smokers, a $53 \%$ excess was detected in the wood workers as compared to the controls, $95 \%$ C.I. 1.23-1.91. Our data support the hypothesis that oxidative stress and lipid peroxidation can have a role in the toxicity of wood dust $\mathrm{F}_{2}$-IsoP measure can be a tool for the evaluation of the effectiveness of targeted interventions aimed to reduce exposures to environmental carcinogens.

Key words: wood dust, organic solvents, formaldehyde, 15- $F_{2 t}$ isoprostane, primary prevention, occupational health. 


\section{Introduction}

1

Wood dust is one of the most common occupational exposures, with about 3.6 million of workers in the wood industry in Europe (Kauppinen et al., 2006). Wood particles can deposit in the nose and the respiratory tract and cause adverse health effects (Çelik and Kanık, 2006). Epidemiological studies have indeed associated the exposure to wood dust to sinonasal cancers (SNC) (Acheson et al., 1968; Ball, 1968). In 1960, the first association with SNC was shown in the wood industry (Acheson et al., 1968). In 1995, this agent was classified as carcinogenic to humans (Group 1) by the International Agency for Research on Cancer (IARC) based mostly on a SNC excess (IARC, 1995). In 2012, the IARC confirmed the human carcinogenicity of wood dust and reported the first link with nasopharynx cancer (IARC, 2012). Considering other types of cancer, a meta-analysis has suggested a relationship with lung cancer (Hancock et al., 2015), but a significant influence of the geographic region was apparent.

SNC has been under compulsory surveillance since 2008 in Italy, through the "Sinonasal Cancer National Registry" (Registro Nazionale Tumori Naso-Sinusali: ReNaTuNS), a nationwide cancer registry coordinated by the National Institute for Insurance Against Accidents at Work (Istituto Nazionale per l'Assicurazione contro gli Infortuni sul Lavoro: INAIL) (Binazzi et al., 2017). Currently, the registry covers a proportion of Italy through regional structures devoted to the active search for cases from hospitals, to the definition of the modalities of exposure and has recorded 1,529 cases between 2000-2016. A study conducted by Demers et al. (Demers et al., 1995) found a doubled risk statistically significant for sinonasal cancer in men employed in any wood-related job $(\mathrm{OR}=2.0,95 \% \mathrm{Cl}: 1.6$ to 2.5$)$ in comparison to men who had never worked in a wood-related job. The increased risk was found among sawmill workers (OR $=2.5,95 \% \mathrm{Cl}: 1.8$ to 3.4 ), furniture workers (OR $=4.5,95 \% \mathrm{Cl}: 3.2$ to 6.5 ) and carpenters (OR $=2.9,95 \% \mathrm{Cl}: 2.1$ to 3.9 ), while no excess risk was observed among forestry, logging, pulp and paper workers. An increasing risk was detected in relation to the duration of exposure, and lagging exposure by 5, 10 or 20 years increased the strength of the association between duration of employment and sinonasal adenocarcinoma. Elevated risk for adenocarcinoma of the nasal cavity and paranasal sinuses (ADCN), a SNC subtype frequently associated with wood dust exposure (IARC, 2012), OR 58.6, 95\% C.I. 23.74-144.8, was even reported among wood workers of the Piedmont region, Italy (d'Errico et al., 2009). Stronger ADCN risk, OR 179.9, 95\% C.I. 55.37-584.4, was found among those workers exposed to high level of wood dust (d'Errico et al., 2009).

Higher levels of oxidative damage, measured by the micronucleus and the comet assays in blood, buccal and nasal cells, have been detected in wood workers compared to unexposed controls (Bruschweiler et al., 2016; Palus et al., 1999; Rekhadevi et al., 2009). An enhanced risk for chromosomal instability was found in wood workers (Bruschweiler et al., 2014; Çelik and Kanık, 2006; Rekhadevi et al., 2009). Discrepant results have been reported (Wultsch et al., 2015). In that study, no induction of micronuclei was observed in wood workers exposed to $0.39-0.66 \mathrm{mg} / \mathrm{m}^{3}$ wood dust levels. Thus, further investigation into wood workers' occupational exposures are warranted. Furthermore, co-exposures to chrome, organic solvents, tannins, formaldehyde, textile dust and pesticides have been reported in the wood industry (Binazzi et al., 2017).In 2012, IARC suggested that the cancer risk of wood workers could be associated with the inflammatory reactions following wood dust exposure rather than to the direct action of this carcinogen (IARC, 2012). Inflammatory cells can generate a large spectrum of proinflammatory mediators and free radicals (Pylkkänen et al., 2009). Excessive production of reactive oxygen species (ROS) can cause damage to lipids, proteins and DNA (Marnett, 2000). Peroxidation of lipids (LPO) can lead to the production of aldehydes, such as malondialdehyde and 4-hydroxynonenal (Marnett, 2000), as well as to secondary oxidation products such as a series of prostaglandin-like products termed isoprostanes (IsoPs) (Roberts and Morrow, 2000).

IsoPs are compounds generated from the non-enzymatic free radical-catalyzed peroxidation of arachidonic acid and other highly unsaturated polyunsaturated fatty acids (Janicka et al., 2010). IsoPs can be grouped into 4 subfamilies, denoted as 5-, 12-, 8-, or 15-series regioisomers, depending on the carbon atom to which the side chain hydroxyl is attached. Among the three major classes of IsoPs $\left(F_{2^{-}}, D_{2^{-}}\right.$and $\left.E_{2^{-}}\right), F_{2^{-}}$-IsoPs are recognized as the most suitable biomarker for 
their chemical stability (Roberts and Morrow, 2000). The measurement of this biomarker is widely used for the analysis of endogenous oxidative stress following ROS production and peroxidation of lipids (Basu, 2008). $\mathrm{F}_{2}$-IsoPs are more advantageous over other LPO biomarkers because they can be detected in a variety of biological samples including plasma, urine, lavage fluid and red blood cells (Milne et al., 2015). As IsoPs generate from LPO, their amounts provide an integrated measurement of unbalanced oxidant-antioxidant status (Lowe et al., 2013; Montuschi et al., 2004).

In the current study, we have investigated the potential effects of occupational exposure to wood dust in the wood product manufacturing sector in the Tuscany Region of Italy. A cross-sectional study was conducted to analyze the concentration of a biomarker of oxidative stress and LPO (15$\mathrm{F}_{2 \mathrm{t}}$-IsoP) in the workers exposed to wood dust. One of the main advantages of using biomarkers is that one can study signals of carcinogen exposure without having to wait for health effects as in classical epidemiological studies (Merlo et al., 1997; Munnia et al., 2017; Munnia et al., 2007; Peluso et al., 1997; Peluso et al., 2012). Although $\mathrm{F}_{2}$-IsoP can be evaluated in different biological fluids, we employed urine due to its ready availability and the high stability of $F_{2}$-IsoP in this medium (Morrow et al., 1999). Since obesity has been associated with increased F2-IsoP concentrations (Annor et al., 2017; Il'yasova et al., 2015), we have examined the relationships between urinary $\mathrm{F}_{2}$-IsoPs and weight gain. Further understanding of the link between wood dust and oxidative stress will improve knowledge of the mechanisms of carcinogenicity of this occupational agent. Novelty of the current study is based on various items, including larger sample size, a different geographical area, and a different type of data, i.e., the measurement of $F_{2}$-IsoPs in urine rather that of micronucleus and DNA strand-breaks in blood, buccal and nasal cells.

\section{Material and methods}

\subsection{Subjects and sampling}

A sample of 44 wood companies of the province of Florence, Tuscany, Italy was randomly selected among those which are under compulsory health surveillance. Wood companies were contacted in person by medical doctors with qualifications in occupational medicine. The inclusion criteria were as follows: (a) only workers exposed to wood dust from wood industry; (b) only workers with a minimal exposure time of 1 year; (c) only controls without occupational history in industries entailing exposure to known or suspected carcinogens; and (d) only controls resident in areas with no proximity to major air pollution sources. All the volunteers involved in the study live and work in the province of Florence, Tuscany, Italy. A 15- $\mathrm{F}_{2} \mathrm{t}-\mathrm{IsoP}$ was determined using spot urine samples collected in the morning at each workplace. Wood workers and the other subjects were contacted by the local occupational health services. All the volunteers were informed about the study aim and gave a written informed consent. A life-style questionnaire was filled by each participant (Peluso et al., 2015). Detailed information on socio-demographic and anthropometric characteristics, education level, exposure to active and passive tobacco smoke, occupational exposure to wood dust, protective gear use, co-exposures to organic solvents, welding and motor exhaust fumes and occupational history were obtained. Subjects who had never smoked were classified as nonsmokers, smokers who had quitted smoking from at least one month prior were classified as exsmokers, while individuals who smoked at least one cigarette per day were classified as smokers. The Body Mass Index (BMI) categories reported from the National Heart National Heart, Lung, and Blood Institute (https://www.nhlbi.nih.gov/) were used for grouping the study participants in normal weight persons $\left(18.5-24.9 \mathrm{~kg} / \mathrm{m}^{2}\right)$, overweight persons $\left(25-25.99 \mathrm{~kg} / \mathrm{m}^{2}\right)$ and obese persons $(\geq 30$ $\mathrm{kg} / \mathrm{m}^{2}$ ). BMI was determined using self-reported weight and height. Study procedures were performed in accordance with the Declaration of Helsinki for human studies and the guidelines of the General Hospital Institutional Committee that reviewed and approved the present protocol.

\subsection{Exposure data}

Data on carcinogen exposure are collected by employers and regularly sent to the Italian Institute for Occupational Safety and Prevention (ISPESL) (Italian legislative decree no. 626 of 19 September 1994). Such information is named exposure registries and includes quantitative measurements of wood dust exposure. Companies are responsible for collecting the exposure 
measurements in accordance with the EN 689:1995 regulation by the European Committee on Standardization (Scarselli et al., 2008). For the purpose of this research, data on occupational exposure measurements of wood dust recorded in the Information System for Recording Occupational Exposures to Carcinogens (SIREP) were used to estimate environmental air concentrations.

\subsection{Urinary $15-F_{2 t}$ isoprostane and creatinine measurement}

The IsoP under investigation consists of one of the most abundant endogenous $\mathrm{F}_{2}$-IsoPs, i.e., the $15-\mathrm{F}_{2 t}-\mathrm{IsoP}$, a biomarker considered to be representative for human oxidant status (Milne et al., 2015), also referred to as 8-iso-prostaglandin $F_{2 a}$ (Roberts and Morrow, 2000). In the current study, the concentrations of $15-\mathrm{F}_{2 t}-$ IsoP were analyzed using the competitive enzyme-linked immunoassay (ELISA) with a specific microplate kit (Oxford, MI, USA), according to the manufacturer's instructions, as previously reported (Bono et al., 2015; Romanazzi et al., 2013). In order to normalize urinary dilution rate of $15-\mathrm{F}_{2 t}$-IsoP an aliquot of urine was used to quantify the concentration of creatinine by the kinetic Jaffé procedure (Bartels and Cikes, 1969).

\subsection{Statistical analysis}

The level of $15-\mathrm{F}_{2 \mathrm{t}}$-IsoP was expressed as $\mathrm{ng} / \mathrm{mg}$ creatinine. Given the right-skewed distribution of this biomarker, the data were log transformed to stabilize the variance and normalize the distribution. Multivariate statistical analyses were applied using log-normal regression models including age (continuous), tobacco smoking, i.e., non-smokers, ex-smokers, smokers, occupational history (years), and BMI, as predictive variables to evaluate the association between exposure to wood dust and the urinary excretion of $15-\mathrm{F}_{2 t}-$ IsoP in the study participants. Results were adjusted for age and smoking. This was based on a previous study showing potential associations between these variables and biomarker levels (Ceppi et al., 2011). Wood workers were classified according to occupational exposures in two additional sub-groups: a) wood workers exposed to wood dust alone and b) wood workers with co-exposures to organic solvents. The regression parameters estimated from the models were interpreted as ratios [Means Ratio (MR)] between the means of $15-\mathrm{F}_{2 t}$-IsoPs of each level of the categorical variables with respect to the reference level, as appropriate. The MR was used as a measure of effect (van Houwelingen et al., 2002). A p-value of $<0.05$ (two-tailed) was considered significant. Data were analyzed using SAS9.3 and SPSS 20.0 (IBM SPSS Statistics, New York, NY).

\section{Results}

\subsection{Study population}

The underlying basic population consisted of workers employed in the wood product manufacturing sector of the province of Florence, Tuscany Region, Italy. 32 out of 44 consented to participate to the study. Participation rates were $\sim 95 \%$. The concentration of $15-\mathrm{F}_{2 \mathrm{t}}-\mathrm{IsoPs}$ in the wood workers was evaluated along with control subjects, i.e., 123 wood workers and 57 controls. All participants were males with a mean age of $45.3 \pm 0.85$ years and $35 \%$ of which were smokers. In the current study, the wood workers consisted of carpenters and joiners, wood processing-plant operators, woodworking machine operators, wood products assemblers, manufacturing labourers, industrial robot operators and other wood related workers. The use of the most common Personal Protective Equipment (PPE) in woodworking, i.e., disposable respirators, was generally reported from majority of the wood workers. Controls were living in residential areas with no proximity to major air pollution sources. The two groups had similar demographic, anthropometric and life-style characteristics. The mean age of the wood workers and the controls was not statistically different (Table 1). The average values of BMI were similar among the two groups (Table 1). The frequency of smokers was similar between the groups, i.e., $36 \%$ of the wood workers and $37 \%$ of the controls, respectively. The distribution of subjects with respect to wood dust exposure with - out co-exposures to other airborne carcinogens and smoking habits was reported in Table 2. Other variables included length of employment and BMI groups (Tables 1-2). 


\subsection{Exposure data}

201

2302

203

204

205

206

9

1287

1208

1309

1410

1351

12612

1213

12814

12915

296

217

2318

219

2द्20

22821

222

2823

224

325

336

327

32 8

35

3829

37

3830

3331

42032

4233

4234

4355

436

457

4738
48

439

540

5241

5342

5243

52544

5245

5746

5847

5248

G 149

The exposure measurement of wood dust air concentrations corresponds to a single value assessed from several consecutive samples by fixed positions (Scarselli et al., 2008). Airborne levels of industrial contaminants were quantified by daily mean concentration, i.e., 8-h timeweighted average (TWA-8), of respirable wood dust among exposed workers. The mean level of TWA-8 concentration of wood dust was $1.48 \mathrm{mg} / \mathrm{m}^{3}$ in wood workers.

\subsection{Urinary $15-F_{2 t}$ isoprostane level, smoking habits and occupational exposure}

An increased amount of $15-\mathrm{F}_{2 \mathrm{t}}$-IsoP was found in the urine of wood workers as compared to the controls (4.2 vs $2.9 \mathrm{ng} / \mathrm{mg}$ creatinine, Table 2). The multivariate analysis shows that the $36 \%$ excess of $15-\mathrm{F}_{2 t}$-IsoP of the wood workers was significantly higher as compared to the controls, $95 \%$ C.I. 1.18-1.57. Smokers had an average concentration of $15-\mathrm{F}_{2 \mathrm{t}}-\mathrm{IsoP}$ higher than ex-smokers and non-smokers. A significant excess was found in the smokers in respect to the non-smokers, 95\% Confidence Interval (C.I.) 1.23-1.66, after adjusting for age by statistical analysis. Subsequently, the effect of co-exposures to other potential occupational carcinogens in the wood industry on the level of $15-\mathrm{F}_{2 t}$ - IsoP was investigated. Therefore, workers were stratified into two additional sub-groups: a) only wood dust exposed workers and b) mixed exposed workers. Table 2 indicates that the highest level of $15-\mathrm{F}_{2 t}$-IsoP occurred in the wood workers who were co-exposed to respirable organic solvents in respect to those who were only exposed to wood dust (4.5 and 4.0 $\mathrm{ng} / \mathrm{mg}$ creatinine, respectively). After adjusting for age and smoking, the multivariate analysis shows a $41 \%$ increment of $15-\mathrm{F}_{2 \mathrm{t}}$ IsoP, $95 \%$ C.I. $1.17-1.70$, in the mixed exposed workers, whereas a lower increment was observed in the only wood dust exposed workers, 95\% C.I. 1.151.56. When we considered occupational history, there was a greater production of $15-\mathrm{F}_{2 \mathrm{t}}$-IsoP in the long-term wood workers $\left(4.8 \mathrm{ng} / \mathrm{mg}\right.$ creatinine of $\left.15-\mathrm{F}_{2 \mathrm{t}}-\mathrm{IsOP}\right)$ compared to those with shorter occupational history $\left(3.2 \mathrm{ng} / \mathrm{mg}\right.$ creatinine). A $41 \%$ excess of $15-\mathrm{F}_{2 \mathrm{t}}$-IsoP was observed in the wood workers with longer occupational exposure times, 95\% C.I. 1.14-1.75. Then, the excretion of $15-\mathrm{F}_{2 \mathrm{t}}$-IsoPs was found to be significantly correlated with the length of dust exposure ( $\mathrm{p}$-value = 0.007). Table 3 reports the mean concentrations of $15-F_{2 t}-I$ soP and MR and $95 \%$ C.I. by exposure group and smoking stratification. The highest amount of $15-\mathrm{F}_{2 \mathrm{t}}-\mathrm{IsoP}$ was found in the wood workers who were smokers, i.e., $5.0 \mathrm{ng} / \mathrm{mg}$.

\subsection{Urinary $15-F_{2 t}$ isoprostane level and BMI groups}

Since early studies have supported the hypothesis of a relationship between $\mathrm{F}_{2}$-IsoP and weight gain (Annor et al., 2017; Il'yasova et al., 2015), the association of this biomarker of oxidant status with BMI was investigated. Study participants were divided by three BMI categories: a) normal weight persons $\left(18.5-24.9 \mathrm{~kg} / \mathrm{m}^{2}\right)$, b) overweight persons $\left(25-25.99 \mathrm{~kg} / \mathrm{m}^{2}\right)$ and c) obese persons $\left(\geq 30 \mathrm{~kg} / \mathrm{m}^{2}\right)$ to evaluate the relationship of $F_{2}$-lsoP with increase in body weight that could result in excessive fat accumulation. Table 2 shows that the mean concentrations of $15-\mathrm{F}_{2 \mathrm{t}}$-IsoP of obese and overweight participants were higher than those with normal weight, but, no significant effect was found.

\section{Discussion}

Wood processing causes small particles of wood dust to become suspended in the air. Workers can inhale these particles, which can cause adverse health effects. The main result of this paper showed that significantly enhanced level of F2-IsoP occurred in the workers compared to the unexposed controls. A $36 \%$ excess of $15-\mathrm{F} 2 \mathrm{t}$-IsoP levels was found in the wood workers as compared with the unexposed controls. Furthermore, the significant excess of 15-F2t-IsoP persisted after smoking habit stratification. Among the wood workers, a 53\% excess of $15-\mathrm{F} 2 \mathrm{t}$-IsoP was found in the smokers, a $48 \%$ excess was observed in the ex-smokers and a $27 \%$ in the nonsmokers as compared to the appropriate controls. The urinary excretion of this biomarker was significantly associated with other parameters, including smoking habits, co-exposure to other airborne carcinogens and length of employment. In particular, multivariate regression analysis showed that the level of $15-\mathrm{F} 2 \mathrm{t}-\mathrm{IsoP}$ was linearly correlated to the length of exposure. In 
agreement with our findings, other studies have previously reported increased oxidative stress generation in relation to occupational exposure to wood dust (Bruschweiler et al., 2016; Palus et al., 1999; Rekhadevi et al., 2009). Our findings provide strengthening of the hypothesis that oxidative stress and LPO can have a main role in the toxicity of wood dust. The analysis of F2-IsoP in urine could offer a unique noninvasive analytic tool to study the role of ROS in chronic occupational exposures. In the current case, the linkage between urinary 15-F2t-IsoPs and wood dust can be due to an increased production of ROS caused by inflammation after exposure fine and abundant airborne dust created during wood manipulation, maintenance activities and cleaning equipment. Increased oxidative stress and LPO can be caused from the oxidative burst of activated macrophages and neutrophils, cells with a main role in phagocytosis and clearance of xenobiotic particles, and from increased inflammatory cytokines and activated leukocytes (Gungor et al., 2010; Vanhees et al., 2013). This is in keeping with the results of previous studies using a biomarker of oxidative DNA damage and LPO (Bonassi et al., 2017; Bono et al., 2016; Bono et al., 2010; Peluso et al., 2013; Peluso et al., 2010). In support of our hypothesis, free radicals produced through chronic inflammatory process and cancer disease have been implicated as the causal factor in the mutagenesis of the tumor suppressor gene TP53 (Brancato et al., 2016; PerezEscuredo et al., 2012).

Next, our study showed an empirical relationship between tobacco smoking and the urinary excretion of $15-\mathrm{F}_{2 \mathrm{t}}-\mathrm{IsoP}$, possibly related to the inhalation exposure to carcinogens contained in tobacco smoke. A $43 \%$ increment of the level of $15-\mathrm{F}_{2 \mathrm{t}}$-IsoP was present in overall the smokers as compared to the non-smokers. This excess is commonly interpreted as an harmful oxidative stress (Basu, 2008). These findings were somewhat expected as active smokers inhale a broad range of airborne carcinogens (IARC, 2004). The involvement of altered oxidative stress-related mechanisms in tobacco smoke carcinogenesis is in line with previous studies using various biomarkers of oxidative stress and LPO (Munnia et al., 2004; Peluso et al., 2014; Romanazzi et al., 2013). Various groups have measured the concentrations of $F_{2}$-IsoP in biological fluids of smokers. The mean level of free and esterified $\mathrm{F}_{2}$-IsoP in the urine and plasma of smokers have been found to be significantly elevated as compared to non-smokers (Lowe et al., 2013). For instance, a previous cross-sectional study conducted on workers employed in an industry of plastic laminates in Piedmont, Italy, founds that smoking habits were significantly associated with the urinary excretion of $15-\mathrm{F}_{2 \mathrm{t}}-\mathrm{IsoP}$ (Romanazzi et al., 2013). When the relationship of $15-\mathrm{F}_{2 \mathrm{t}}$-IsoP with BMI was investigated, we found that the levels of $15-\mathrm{F}_{2 \mathrm{t}}$-IsoP tended to increase with fat accumulations. The $42 \%$ of the obese subjects showed indeed higher excretion of $15-\mathrm{F}_{2 t}-\mathrm{IsoP}$ in respect to those with normal weight. This is partially in keeping with a previous work of Annor et al. (Annor et al., 2017) on the risk of diabetes and weight gain. In that study, the $35 \%$ of the obese individuals showed greater levels of $\mathrm{F}_{2}$-IsoPs as compared to the controls. Additional studies are necessary to understand if this biomarker can be used as measure of lifestyle habits and intervention targeted to obesity prevention.

The threshold exposure limit recommended by the Italian law is $5 \mathrm{mg} / \mathrm{m}^{3}$ (Legislative Decree No $66 / 2000$ ). This value will remain until the $2020^{\text {th }}$, after the entry into force of the new threshold exposure limit of $3 \mathrm{mg} / \mathrm{m}^{3}$ for five years and thereafter of $2 \mathrm{mg} / \mathrm{m}^{3}$ (European Directive Decree No 2017/2398). In this context, the SIREP database aims to facilitate analysis of occupational exposure figures for carcinogenic agents. In or study, the average amount of wood dust concentrations experienced from the wood workers was lower than threshold exposure limit of 3 $\mathrm{mg} / \mathrm{m}^{3}$ (i.e., $1.48 \mathrm{mg} / \mathrm{m}^{3}$ ). This result is consistent with that reported from a previous study of Scarselli et al. (Scarselli et al., 2008), where the mean concentrations of wood dust was of 1.44 $\mathrm{mg} / \mathrm{m}^{3}$ for 1.181 companies in Italy. Although our static measurements of the concentrations of industrial contaminants by fixed positions provide evidence of wood workers' exposure via air, they are not well representative of individual exposures to wood dust due to spatial and temporal variations. Therefore, we could not assess the potential relationships of airborne measurements with biomarker urinary excretion in exposed workers.

The airborne wood-dust concentrations from exposure registries are commonly used for the purposes of hazard control, exposure surveillance and assessment of health risks (Kauppinen et 
al., 2006). Nevertheless, a limitation of our study is that no data on the variability of wood dust concentrations within a facility were available. The bias due to the variability of airborne carcinogen levels in occupational settings is difficult to predict, but a large variation can be present in one spot of a factory versus another. There could be an underestimation of the exposure to wood dust associated to some woodworking operations. For instance, local exhaust ventilation is used widely with fixed woodworking machinery, but it is generally lacking for hand tools (Pisaniello et al., 1991). The effects of poor work practices, such as the use of compressed air for cleaning, the lack of local exhaust ventilation for hand tools, that are commonly associated to high exposure levels to wood dust (Alwis et al., 1999), could be missed. Variations in the use of PPE (Alwis et al., 1999) and in the effective application of WorkSafe procedures at work places could have influenced the personal levels of exposure to wood dust of our workers.

Our subsequent finding shows that the urinary excretion of $15-\mathrm{F}_{2 \mathrm{t}}-\mathrm{IsoP}$ in the workers exposed to wood dust can aggravate with co-exposure to other respiratory carcinogens. An excess of $41 \%$ was detected in the wood workers that were co-exposed to organic solvents compared to the controls. Conversely, a lower excess was determined in the only wood dust exposed workers. High biosynthesis of $\mathrm{F}_{2}$-IsoP can be due to frequent free radical-catalyzed reactions induced by alterations of oxidative stress, antioxidant defence and inflammation especially caused by occupational exposures to complex mixtures of airborne carcinogens. This is consistent with a cross-sectional study of workers exposed to dust containing silica (Peluso et al., 2015). In this study, the amount of oxidative stress and LPO biomarker of the workers exposed to airborne silica dust was greater in the case of occupational co-exposures to organic solvents, welding and motor exhaust fumes. Constituents of organic solvents, such as benzene and formaldehyde can be involved in the generation of oxidative stress and ROS (Bono et al., 2016; Bono et al., 2010; Sorensen et al., 2003) and cause the production of 15- $\mathrm{F}_{2 \mathrm{t}}$-lsoP determined in the workers exposed to wood dust. Our results suggest that the urinary level of $F_{2}$-IsoP resulting from exposures to airborne wood dust can be affected from concomitant carcinogen exposures. Levels of oxidative stress can increase with exposures to organic solvents (Salimi et al., 2017; Singh et al., 2010), leading to a greater imbalance between excessive ROS generation and their degradation by antioxidants. The induction of reactive species can increase damage to membrane lipids, cellular proteins and DNA.

A significant difference in the amount of $15-\mathrm{F}_{2 \mathrm{t}}$-IsoP was then observed among sub-groups of wood workers with different occupational history. The urinary excretion of this biomarker of oxidant status was significantly elevated in those subjects with longer exposure time. An $41 \%$ excess of $15-\mathrm{F}_{2 t^{-}}$ IsoP was found in the long-term wood workers as compared to those with shorter exposures, used as the reference level. Multivariate regression analysis showed that the level of $15-\mathrm{F}_{2 \mathrm{t}}$-IsoP was significantly linearly correlated to the length of employment, in agreement with a previous study on asbestos workers (Yoshida et al., 2001). In that study, the generation of an urinary biomarker of oxidative stress correlated positively with the length of exposure. Rekhadevi et al. (Rekhadevi et al., 2009) have similarly found an association between length of occupational exposure and increase frequency of micronuclei. Taken together, the occurrence of elevated oxidative stress in long-term wood workers can be possibly due to chronic inflammatory conditions. Our study suggests that the measure of urinary F2-IsoPs can serve as a biomarker for assessing occupational carcinogen exposure and improving workplace safety. Particular effort should bedevoted to studyinglong termhealth effects of exposure to wood dust,such as SNC.

Particular effort should be devoted to study delayed reactions such as diseases that take a long time to develop, like SNC, that can be caused by long-term exposure to this carcinogenic agent.

\section{Conclusions}

Our study provides a valuable contribution to the issue of oxidative stress in woodworking. An excessive ROS generation was demonstrated in exposed workers. Furthermore, we showed that exposure to organic solvents can increase the levels of urinary biomarkers of oxidative stress in wood workers. Results provide a basis for worker surveillance in occupational settings. $\mathrm{F}_{2}$-IsoP measure could be used for the evaluation of the effectiveness of targeted interventions aimed to 
reduce exposures to various environmental carcinogens. A more effective control of occupational health risks could decrease the incidence of illness at work and improve the health of the workforce. Acknowledgments

We are grateful to Dr. Dusca Bartoli, Dr. Giuseppe A. Farina, Dr. Tonina E. Iaia, Dr. Pierluigi Faina, Dr. Luciano Monticelli for the assistances contacting with workers.

\section{Funding}

This work was supported by the Tuscany Region and the National Institute for Insurance Against Accident at Work (INAIL).

1566 None 
Annor, F., et al., 2017. African Ancestry Gradient Is Associated with Lower Systemic F(2)-Isoprostane Levels. Oxid Med Cell Longev. 2017, 8319176-8319176.

Ball, M. J., 1968. Nasal cancer in woodworkers. Br Med J. 3, 253-253.

Bartels, H., Cikes, M., 1969. [Chromogens in the creatinine determination of Jaffe]. Clin Chim Acta. 26, 1-10.

Basu, S., 2008. F2-isoprostanes in human health and diseases: from molecular mechanisms to clinical implications. Antiox Redox Sign. 10, 1405-1434.

Binazzi, A., et al., 2017. Sinonasal cancer in the Italian national surveillance system: Epidemiology, occupation, and public health implications. Am J Ind Med. 1-12.

Bonassi, S., et al., 2017. 3-(2-deoxy- $\beta$-d-erythro-pentafuranosyl) pyrimido $[1,2-\alpha]$ purin-10 (3H)-one deoxyguanosine adducts of workers exposed to asbestos fibers. Toxic Lett. 270, 1-7.

Bono, R., et al., 2016. Formaldehyde-induced toxicity in the nasal epithelia of workers of a plastic laminate plant. Toxicol Res. 5, 752-760.

Bono, R., et al., 2010. Malondialdehyde-deoxyguanosine adduct formation in workers of pathology wards: the role of air formaldehyde exposure. Chem Res Toxicol. 23, 1342-8.

Bono, R., et al., 2015. Urban air and tobacco smoke as conditions that increase the risk of oxidative stress and respiratory response in youth. Environ Res. 137, 141-146.

Brancato, B., et al., 2016. 8-Oxo-7, 8-dihydro-2-deoxyguanosine and other lesions along the coding strand of the exon 5 of the tumour suppressor gene P53 in a breast cancer case-control study. DNA Res. 23, 395-402.

Bruschweiler, D. E., et al., 2016. DNA Damage among Wood Workers Assessed with the Comet Assay. Environ Health Insights. 10, 105-112.

Bruschweiler, E. D., et al., 2014. Workers exposed to wood dust have an increased micronucleus frequency in nasal and buccal cells: results from a pilot study. Mutagenesis. 29, 201-207.

Çelik, A., Kanık, A., 2006. Genotoxicity of occupational exposure to wood dust: Micronucleus frequency and nuclear changes in exfoliated buccal mucosa cells. Environ Mol Mutagen. 47, 693-698.

Ceppi, M., et al., 2011. Study design and statistical analysis of data in human population studies with the micronucleus assay. Mutagenesis. 26, 247-252.

d'Errico, A., et al., 2009. A case-control study on occupational risk factors for sino-nasal cancer. Occup Environ Med. 66, 448-455.

Demers, P. A., et al., 1995. Wood dust and sino-nasal cancer: pooled reanalysis of twelve case-control studies. Am J Ind Med. 28, 151-66.

Gungor, N., et al., 2010. Transcriptional profiling of the acute pulmonary inflammatory response induced by LPS: role of neutrophils. Respir Res. 11, 24.

Hancock, D. G., et al., 2015. Wood dust exposure and lung cancer risk: a meta-analysis. Occup Environ Med. 72, 889-898.

IARC, 1995. Wood Dust and Formaldehyde. IARC Monogr Eval Carcinog Risk Chem Hum. 62, 35-215.

IARC, 2004. Tobacco smoke and involuntary smoking. IARC Monogr Eval Carcinog Risks Hum. 83, 1-1438.

IARC, 2012. Wood Dust. A Review of Human Carcinogens: Arsenic, Metals, Fibres, and Dusts. IARC Monogr Eval Carcinog Risks Hum. 100 C, 1-469.

II'yasova, D., et al., 2015. Urinary F2-Isoprostanes and Metabolic Markers of Fat Oxidation. Oxid Medic Cell Long. 2015.

Janicka, M., et al., 2010. Isoprostanes-Biomarkers of Lipid Peroxidation: Their Utility in Evaluating Oxidative Stress and Analysis. IJMS. 11, 4631.

Kauppinen, T., et al., 2006. Occupational Exposure to Inhalable Wood Dust in the Member States of the European Union. Ann Occ Hyg. 50, 549-561.

Lowe, F. J., et al., 2013. Lung cancer biomarkers for the assessment of modified risk tobacco products: an oxidative stress perspective. Biomarkers. 18, 183-195.

Marnett, L. J., 2000. Oxyradicals and DNA damage. Carcinogenesis. 21, 361-70. 
Merlo, F., et al., 1997. Airborne levels of polycyclic aromatic hydrocarbons: 32P-postlabeling DNA adducts and micronuclei in white blood cells from traffic police workers and urban residents. J Environ Pathol Toxicol Oncol. 16, 157-62.

Milne, L. G., et al., 2015. The isoprostanes - 25 years later. BBA-Mol Cell Biol L. 1851, 433-445.

Montuschi, P., et al., 2004. Isoprostanes: markers and mediators of oxidative stress. FASEB. 18, $1791-1800$.

Morrow, J. D., et al., 1999. Quantification of the Major Urinary Metabolite of 15-F2t-Isoprostane (8-isoPGF2Î士) by a Stable Isotope Dilution Mass Spectrometric Assay. Anal Bioch. 269, 326-331.

Munnia, A., et al., 2004. Exocyclic malondialdehyde and aromatic DNA adducts in larynx tissues. Free Radic Biol Med. 37, 850-8.

Munnia, A., et al., 2017. Bulky DNA Adducts, Tobacco Smoking, Genetic Susceptibility, and Lung Cancer Risk. Adv Clin Chem. 81, 231-77.

Munnia, A., et al., 2007. 32P-Post-labelling method improvements for aromatic compound-related molecular epidemiology studies. Mutagenesis. 22, 381-5.

Palus, J., et al., 1999. DNA damage detected by the comet assay in the white blood cells of workers in a wooden furniture plant. Mutat Res. 444, 61-74.

Peluso, M., et al., 1997. Detection of DNA adducts in human nasal mucosa tissue by 32P-postlabeling analysis. Carcinogenesis. 18, 339-44.

Peluso, M., et al., 2012. DNA methylation differences in exposed workers and nearby residents of the Ma Ta Phut industrial estate, Rayong, Thailand. Int J Epidemiol. 41, 1753-60; author response 1761-3.

Peluso, M., et al., 2013. Malondialdehyde-deoxyguanosine and bulky DNA adducts in schoolchildren resident in the proximity of the Sarroch industrial estate on Sardinia Island, Italy. Mutagenesis. 28, 315-21.

Peluso, M., et al., 2010. Malondialdehyde-deoxyguanosine adducts among workers of a Thai industrial estate and nearby residents. Environ Health Perspect. 118, 55-9.

Peluso, M. E., et al., 2014. Aberrant methylation of hypermethylated-in-cancer-1 and exocyclic DNA adducts in tobacco smokers. Toxicol Sci. 137, 47-54.

Peluso, M. E., et al., 2015. Oxidatively damaged DNA in the nasal epithelium of workers occupationally exposed to silica dust in Tuscany region, Italy. Mutagenesis. 30, 519-25.

Perez-Escuredo, J., et al., 2012. Wood dust-related mutational profile of TP53 in intestinal-type sinonasal adenocarcinoma. Human Pathology. 43, 1894-1901.

Pisaniello, D. L., et al., 1991. Wood dust exposure during furniture manufacture -results from an Australian survey and consideration for threshold limit value development. Am Ind Hyg Ass J. 52, 485-492.

Pylkkänen, L., et al., 2009. Wood dusts induce the production of reactive oxygen species and caspase-3 activity in human bronchial epithelial cells. Toxic in Vitro. 262, 265-270.

Rekhadevi, P. V., et al., 2009. Genetic damage in wood dust-exposed workers. Mutagenesis. 24, 59-65.

Roberts, L. J., Morrow, J. D., 2000. Measurement of F2-isoprostanes as an index of oxidative stress in vivo. Free Radic Biol Med. 28, 505-513.

Romanazzi, V., et al., 2013. 15-F(2)t isoprostane as biomarker of oxidative stress induced by tobacco smoke and occupational exposure to formaldehyde in workers of plastic laminates. Sci Total Environ. 442, 20-5.

Salimi, A., et al., 2017. Xylene Induces Oxidative Stress and Mitochondria Damage in Isolated Human Lymphocytes. Toxic res. 33, 233-238.

Scarselli, A., et al., 2008. Occupational exposure levels to wood dust in Italy, 1996\&\#x2013;2006. Occup Environ Med. 65, 567-574.

Singh, M. P., et al., 2010. Effects of co-exposure of benzene, toluene and xylene to Drosophila melanogaster: Alteration in hsp70, hsp60, hsp83, hsp26, ROS generation and oxidative stress markers. Chemosphere. 79, 577-587.

Sorensen, M., et al., 2003. Linking exposure to environmental pollutants with biological effects. Mutat Res. 544, 255-71.

van Houwelingen, H. C., et al., 2002. Advanced methods in meta-analysis: multivariate approach and metaregression. Stat Med. 21, 589-624. 
Vanhees, K., et al., 2013. Intrauterine exposure to flavonoids modifies antioxidant status at adulthood and decreases oxidative stress-induced DNA damage. Free Radic Biol Med. 57, 154-61.

Wultsch, G., et al., 2015. Impact of exposure to wood dust on genotoxicity and cytotoxicity in exfoliated buccal and nasal cells. Mutagenesis. 30, 701-709.

Yoshida, R., et al., 2001. Urinary 8-oxo-7, 8-dihydro-2'-deoxyguanosine and biopyrrins levels among construction workers with asbestos exposure history. Ind Health. 39, 186-8. 


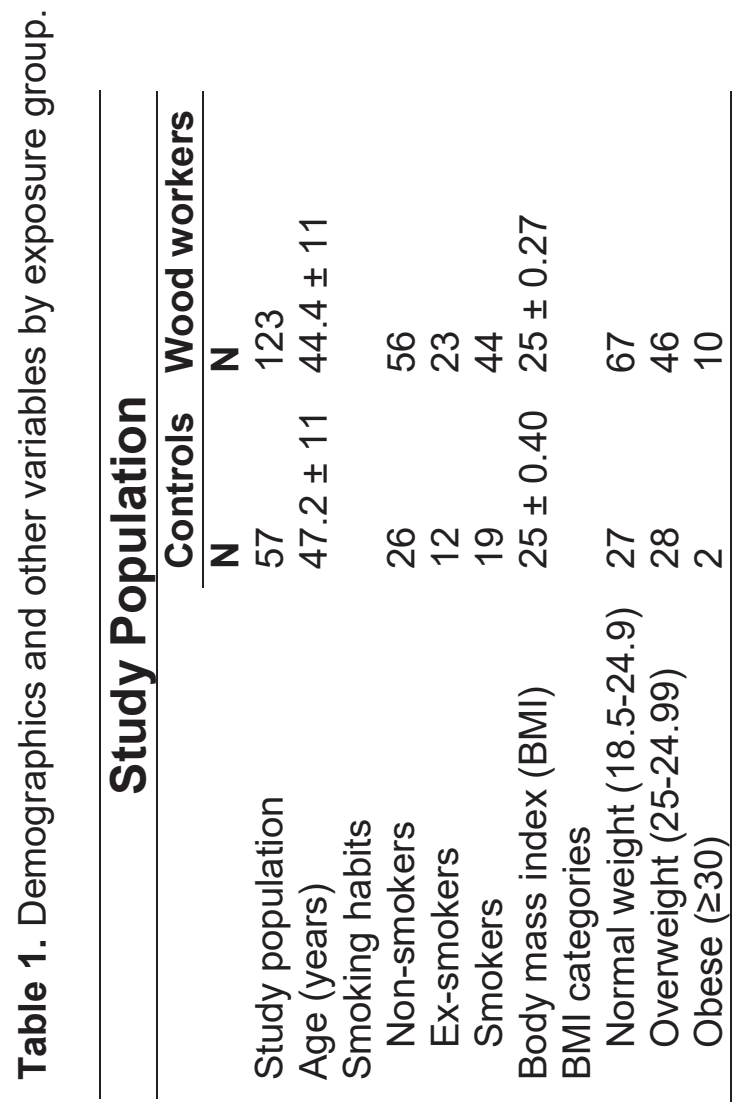




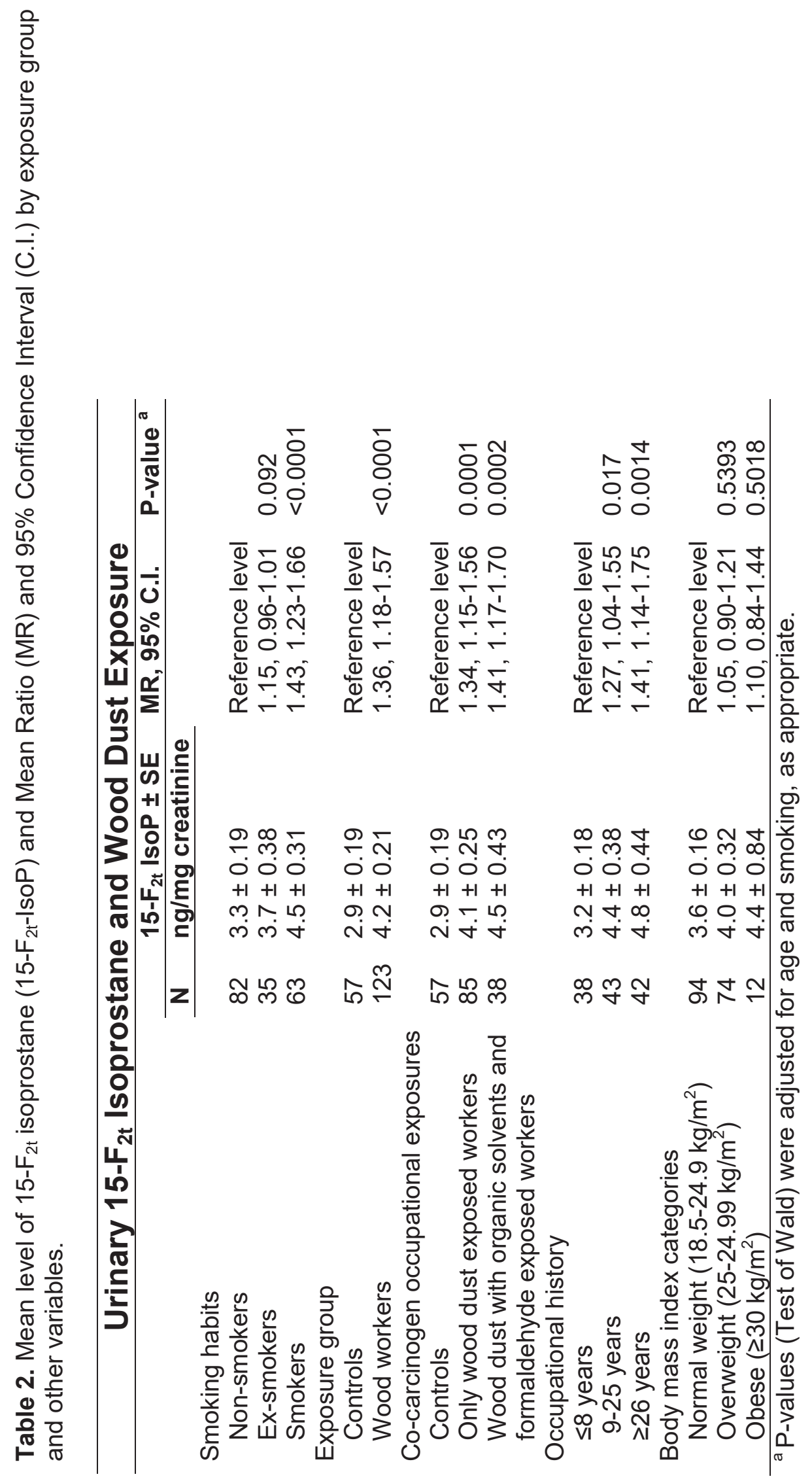




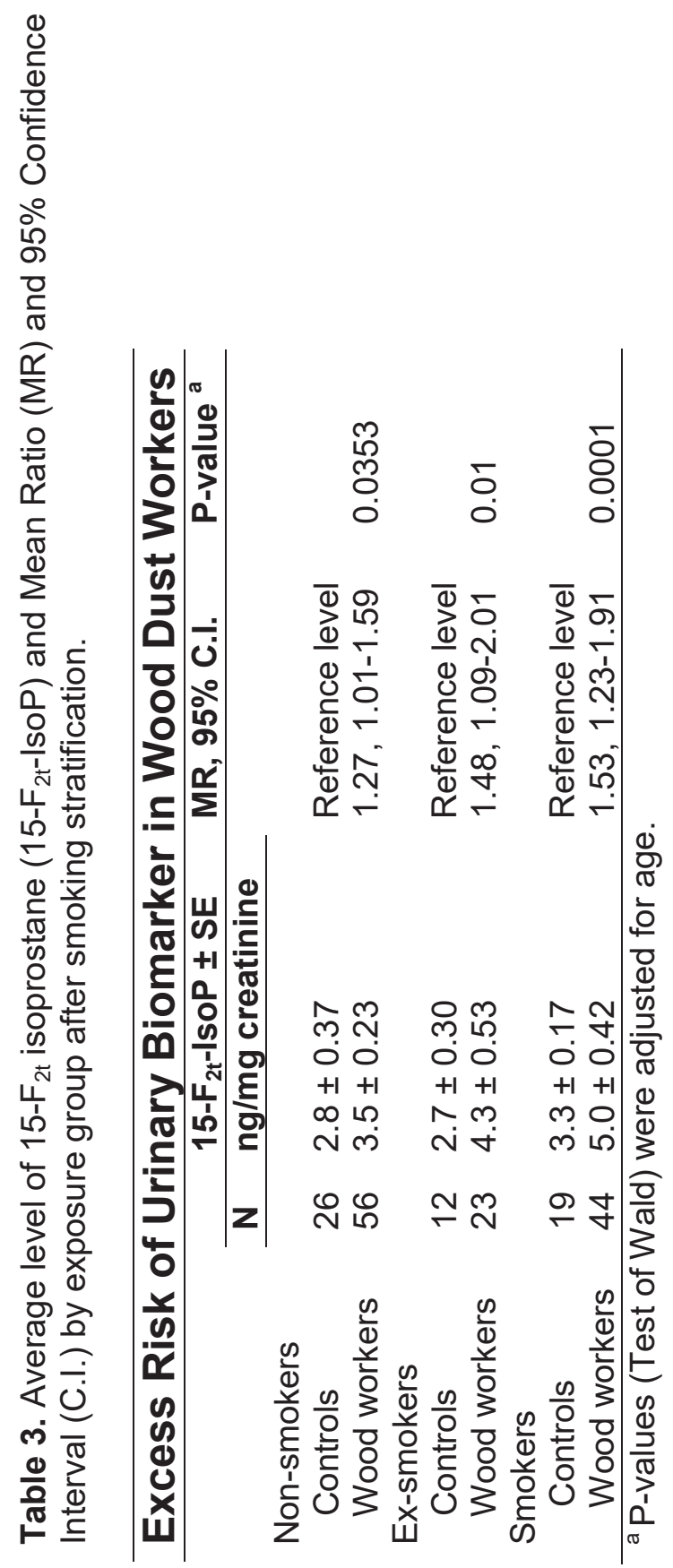

